\title{
ASPECTOS IBÉRICOS NA LÍNGUA PORTUGUESA
}

\section{WILSON TAVEIRA DE LOS SANTOS}

\section{Resumo:}

O presente estudo objetiva apontar alguns aspectos da formação da Língua Portuguesa através dos séculos.

É notório que a Língua Portuguesa tem recebido, ao longo do tempo, contribuições vernaculares de diversas origens ligüísticas. Nossa língua, como muitas outras, é dinâmica. Portanto,o próprio conhecimento lingüístico, considerando o aspecto semântico ou vernacular, é interes sante, informativo e relevante para todos aqueles que buscam conhecimen to mais fundamentado neste campo.

A seguir apresentaremos uma resenha histórica de nossa língua em uma pesquisa etimológica de dois vocábulos, a saber, arroio e perro.

Arroio designa um curso pequeno de água, geralmente de origem irregular. No Uruguai, muitas pessoas se referem ao "Rio Quaraí" como "Arroio Quaraí - divisa fluvial entre o Uruguai e o Rio Grande do Sul. Este rio é afluente do Rio Uruguai e sua desembocadura localiza-se nas proximidades da cidade brasileira chamada Uruguaiana. Este rio nunca se ca, embora haja, ocasionalmente, longa estiagem. Contrariamente ao expos to no dicionário etimológico, "...pequeno curso de água, permanente ou não" (Novo Dicionário, Aurélio Buarque de Holanda, Editora Nova Frontei ra, RJ), este rio poder-se-ia comparar, em alguns trechos, com o Rio Tie tê em São Paulo.

O vocábulo perro, designativo de "cão" em espanhol ("can"), é de uso restrito, porém analogamente ao vocábulo analisado anteriormente, não é de origem latina.

Sabe-se que a Língua Portuguesa se formou na Península Ibérica por transformação do latim, que foi levado até ali pela conquista e colonização romanas. O latim era a língua falada no Látio ou Lácio, região da Itália, onde foi fundada a cidade de Roma. Os romanos estenderam seus domínios e impuseram seu idioma mediante a expansão política, pela Península Ibérica e mais tarde por todo o mundo conhecido. O latim foi, portanto, um poderoso instrumento de unificação do Império Romano.

A romanização levou às diversas províncias o latim tal como era falado pelos legionários, comerciantes, funcionários administrativos e colonos em geral. Era uma língua distinta à que empregavam os escritores latinos, cujas obras se estudam até os dias de hoje como paradigma de correção e elegância lingüístca. Esta língua escrita é o latim literário, o seja, o latim clássico. A língua falada pelo povo era o latim vulgar. Contudo, não devemos supor que este era o modo incorreto de se falar, mas que era a maneira habitual e corrente de empregar o latim.

A extensão do latim em todo o império não foi simultânea nem uniforme. Em algumas regiões não desarraigou completamente as línguas nacionais. O grego, instrumento de uma cultura superior, realizou um processo inverso; o latim, devido a sua influência, tornou-se mais flexível, mais rico, mais amplo. Logo incorporou muitas palavras gregas que prontamente se propagaram por todo o Império. Esta é a origem dos antigos 
helenismos do nosso idioma.

A Península Ibérica foi romanizada muito cedo. No final do século III a.C., Roma encontrou ali grande profusão de povos (celtas, iberos, tartésios) e os unificou na organização civil, nos costumes, nas vestimentas e, sobretudo no idioma. Apenas o basco-cantábrico resistiu, em termos ligüísticos. A origem deste povo e de sua língua permanecem ainda desconhecidas.

Os outros idiomas desapareceram e o latim se enraizou profundamente. Como língua culta era ensinado nas escolas e o cristianismo, de pronta difusão na península, contribuiu enormemente para o afiançamento do latim, pois o empregava para o culto litúrgico e a pregação. Apesar de tudo isso, permaneceram ainda alguns rasgos e vocábulos das línguas primitivas.

Os rasgos das línguas primitivas que permaneceram no latim vulgar são de natureza fonética, léxica e morfológica. Quando Adriano, nascido na Espanha, era apenas um questor, pronunciou-se perante o Senado Romano e devido ao seu acento (sotaque) estrangeiro, causou hilariedade entre os ouvintes. Após este fato, preocupou-se em eliminar esta característica provinciana e, ao tornar-se imperador, distinguiu-se por sua perícia ao falar latim.

As questões léxicas também tiveram notoriedade. As línguas pré-românicas transmitiram ao latim algumas palavras, aproximadamente trinta, cuja origem não está satisfatoriamente determinada. Entre elas estão: balsa, gordo, barro, cama, gancho, lousa, manteiga, colmeia, rocha, sapo, arroio (provavelmente de origem ibérica). A palabra perro que significa "cão" é, quiçá, proveniente de um vocábulo céltico que significava quadrúpede.

Os traços morfológicos, os sufixos dos patronímicos '-es': Sancho - Sanches; Rodrigo Rodrigues; Fernado - Fernandes, etc. e, talvez, o dininutivo '-ico' e alguns outros.

A Península lbérica teve, pois, como língua única, cultural e popular a latim e o transmitiu aos povos visigodos (bárbaros germânicos) que invadiram a península no século $V$ de nossa era. Estas, por sua vez, esqueceram sua língua e adotaram o latim que continuou sendo a língua peninsular.

Vocábulos de origem germânica foram incorporados a nossa língua. Citam-se entre outros os seguintes (nomes próprios): Ramiro, Beltrão, Gusmão, Afonso ou Alfonso, Elvira, Fernando, Gonçalo; (outros nomes): agasalhar, arenque, branco, coifa, dardo, escárnio, espião, esquilar, esquina, esquivar, estribo, falda, feudo, feltro, ganhar, guarda, guerra, guisa, godo, gris, guante, guarecer, guarnecer, heraldo, rico, roubar, tapa, trégua, trotar, etc. (Vide Aurélio Buarque de Holanda Ferreira, Novo Dicionário da Língua Portuguesa, Editora Nova Fronteira, 1986 e Maria López Blanque, Lecciones de Lenguaje).

Com o desmembramento do Império Romano surgiu a decadência cultural e a ruptura da unidade lingüística. Interrom- peram-se as comunicações, desapareceram as escolas latinas que contribuiam poderosamente para o estabelecimento dessa unidade $e$ aperfeiçoamento no uso da língua. O latim se transformou, em cada província ou em cada região, de uma maneira particular, o que originou o surgimento de línguas românicas, romances e neolatinas, derivadas do latim, separadas por divergências cada vez mais profundas devido a características geográficas e étnicas. São línguas românicas ou romances: o romeno, o dálmata, o rético, o italiano, o sardo, o francês, o provençal, o catalão, o espanhol, o galego e o português.

O latim-espanhol experimentou durante o período visigodo notáveis alterações que o foram caracterizando progressivamente como língua romance.

Por outro lado, o português recebeu vocábulos de origem ibérica. Os íberos eram um povo que já habitava a Península ibérica antes da colonização romana. Este povo provavelmente caucasiano, nos deixou alguns vocábulos que transcenderam as fronteiras do tempo e da geografia. Consideraremos, então, dois: arroio e perro, retirados do 
"Dicionário Etimológico da Língua portuguesa" de Antenor Nascentes, Rio de Janeiro, 1955.

ARROIO - De or. ibérica (M. Lübke, REW, 678 e Gram., I § 21. O lat. arrugia, galeria nas minas, aparece em Plínio, Hist. nat., XXXIII, § 70. Em documentos asturianos medievais há arogium e arrogium (Tailhan, Romania, IX, 430), já arrouim no séc. IX. Em documentos portugueses medievais há arrugium e arroio: Discuriti ipso pomare per arrugium...

(Diplom., p. 49-A960). Et inde per illo arroio... (ib., p. 1-A 773), apud Cortesão, Subs. V. Leite de Vasconcelos, Lições de Filologia, p. 119, nota 2 . 0 esp. tem arroyo, 0 it roggia. Diez Dic., 426, rejeita o lat. rivu, rio. A vista do parentesco com o lat. corrugs e com o gr. orué, excavação, Mégacles, RLP, XXVI, pg. 78, rejeita o étmo. semítico proposto por

Keller, Volksetym, 192.

PERRO - Talvez de origem ibérica (M. Lübke, Gram., 1, 47, REW, 6449, Zeitschrift rom. Phil., XXIII, 199). M. Lübke rejeita a derivação de Pedro (Diez, Dic., 476). João Ribeiro, Seleta Clássica, nota 57, tira do lat. patriu. Pacheco e Lameira, Gram. Port., 222, derivam sânscr. parria, pariah, de para, fora de: cachorro sem dono nem casa. A Academia Espanhola prendeu o esp. perro ao lat. petro, rústico, com alusão ao canis petronius, cão que caça nos penhascos. A. Coelho tirou do esp. Eguilaz diz que Marina liga ao ár. diru, cão de caça. Diez relaciona com o b. lat. petrunculus canis; Donkin, em dúvida, com o céltico, dizendo ser no Principado de Gales o nome comum do cachorro. 0 adj. verro deve ser adverbal de emperrar.

Do "Novo Dicionário Aurélio" de Aurélio Buarque de Holanda, Editora Nova Fronteira, Rio de Janeiro, 1986, extraímos:

arroiar. V. int. Correr ou manar mansamente como arroio. [Conj.: v. apoiar. Pres. ind.: arróio, etc. Cf. arroio.] arroio. [Do lat. vulg. arrugiu] S. m. 1. Pequeno curso de água, permanente ou não: "Murmurava um arroio de água pura; os medronheiros estavam cobertos de frutos maduros" (Aquino Ribeiro, Dom Frei Bartolomeu, p. 58). 2. -equena correinte de qualquer líquido. (Cf. arroio, do v. arroiar].

Em "Superfície da Terra" de Bloom, Arthur L., Ed. Edgar Blüscher Ltda, 1970, SP, encontramos:

"... Na América Latina e no sudoeste hispano-americano dos Estados Unidos, os canais fluviais são chamados arroyos. Em partes do Saara, de fala francesa, são os onadis, derivação óbvia do termo árabe original, wadi. Outros Termos descritivos são wash e draw. (...) Todo o fundo do arroyo será lavado durante o escoamento. (...) A 
declividade dos arroyos é íngreme, em conseqüência da carga excessiva de sedimentos. (...) A superfície de um leque aluvial é a continuação, para baixo do declive íngreme do talvegue de um canhão ou arroyo"

Do "Dicionário Geológico - Geomorfológico", IBGE - 1979, de Guerra Antonio Teixeira, extraímos:

arroio - denominação dada aos pequenos rios do sul do Brasil, ex.: Arroio Xuí (Rio Grande do Sul). Corresponde aos igarapés (vide) região amazônica. Em Curitiba, verificamos a existência do Arroio Cachoeira no Bairro Cachoeira. Nos Estados do Rio Grande do Sul e Santa Catarina, o uso do vocábulo arroio ocorre em profusão para designar qualquer curso de água maior a uma "sanga".

No "Webster's Encyclopedic Unabrigded Dictionary of de English Language", Didilthium Press, Ltd, 1989, encontramos:

ar.roy.o, $\mathrm{n}$, pl. - os. (chiefly in southwest U.S.) a small steep-sided watercouse or gulch with a nearly flat floor: usually dry except after heavy rains [ $<\mathrm{Sp}$; akin to Larrugia mine-shaft]. Arroy/o Gran/de, a town in SW California, 3291 (1960).

No sudoeste dos Estados Unidos, o vocábulo arroyo é muito conhecido e usado. Evidentemente, devido a influência do espanhol oriundo do México.

Como podemos observar pelos dois exemplos apresentados, perro e arroio não são de origem latina, embora esta língua represente uma grande proporção na formação da Língua portuguesa, outros troncos lingüísticos também contribuíram com alguns vocábulos que chegaram até nossos tempos.

Domingos José Gonçalves de Magalhães, no prefácio de seu livros "Suspiros Poéticos e Saudades", 1836, nos lembra: "... mas línguas vivas se enriquecem com progresso da civilização, e das ciências, e uma nova idéia pede um novo termo 